\title{
Farklı Arazi Kullanımı Altındaki Podzolik Toprakların Kalite Parametrelerinin Belirlenmesi*
}

\author{
Miraç GÜLNAR $^{1} \quad$ Kenan BARÍK ${ }^{2 * *}$ \\ ${ }^{1}$ T.C. Ticaret Bakanlığı, Doğu Karadeniz Bölge Müdürlüğü, Trabzon, Türkiye \\ ${ }^{2}$ Atatürk Üniversitesi, Ziraat Fakültesi, Toprak Bilimi ve Bitki Besleme Bölümü, Erzurum, Türkiye \\ (**Sorumlu yazar e-mail: kbarik@atauni.edu.tr) \\ DOI: 10.17097/ataunizfd.480971
}

\author{
Geliş Tarihi (Received Date): 09.11.2018
}

Kabul Tarihi (Accepted Date): 05.02.2019

\begin{abstract}
ÖZ: Bu çalışmanın amacı Doğu Karadeniz Bölgesinde yaygın olarak bulunan podzolik toprakların farklı kullanım koşulları altındaki durumlarını toprak kalite parametrelerine göre değerlendirmek amacıyla yürütülmüștür. Rize ili sınırları içerisinde çay tarımı yapılan arazi, çayır ve orman örtüsüyle kaplı araziler çalışma alanı olarak belirlenmiştir. Belirlenen her bir arazide toprak profili açıımış ve profil tanımlaması yapılmışıı. Alınan toprak örnekleri ile toprak kalitesini belirleyen parametrelere göre çeşitli kimyasal ve fiziksel analizler yapılmıştır. Araştırmada, alınan toprak örneklerinin tekstür, toprak reaksiyonu, kireç, organik madde, elektrik iletkenliği, katyon değişim kapasitesi, değişebilir katyon, azot, fosfor, mikroelement, tane yoğunluğu, agregat stabilitesi, hidrolik iletkenlik durumları değerlendirilmiștir. Yapılan değerlendirmeler sonucunda arazi kullanım şekline göre her üç şekilde kullanılan arazilerinde değerledirilen 4 farklı yöteme göre kaliteli oldukları görülmüş olup; çayır ve orman örtüsüyle kaplı arazilerin toprak kalitesinin çay tarımı yapılan araziye göre daha yüksek olduğu belirlenmiştir.
\end{abstract}

Anahtar Kelimeler: Toprak kalitesi, Toprak kalite indeksi, Podzolik topraklar

\section{Determination of Quality Parameters of Podzolic Soils Under Different Land Use}

\begin{abstract}
ABSRTACT: The aim of this study is to evaluate the status of podzolic soils commonly found in the Eastern Black Sea Region, under different land use conditions in terms of soil quality parameters. Cultivated area used for tea garden, meadow and forest lands were determined as the study area. The soil profiles for each determined lands were excavated and defined. The study was done with soil samples taken from each horizonsof profiles. Some chemical and physical analyses were carried out with these samples based on soil quality parameters. In this study, the texture, soil acidity, lime contend, organic material, electric conductivity, cation exchange capacity, exchangeable cation, nitrogen, phosphorus, microelement, particle density, aggregate stability, hydraulic conductivity of these soil samples were evaluated. As a result of these evaluations, it is found all land use types has high land quality. On the other hand, it was also determined that the soil quality of meadow and forest lands were higher than the tea cultivating lands.
\end{abstract}

Keywords: Soil, Soil quality, Soil quality index, Podzolic soils

*Bu çalışma, Miraç Gülnar'ın Yüksek Lisans Tezi'nden üretilmiş ve Atatürk Üniversitesi BAP birimi (2012-406 nolu proje) tarafindan desteklenmiştir.

\section{GÍRIS}

Son yillarda toprak bilimindeki gelişmeler ile birlikte toprak kalitesi ilgi çeken bir konu haline gelmiştir. Toprak kalitesinin geliştirilmesi, korunması ve sürdürülebilirliği ile birlikte tarımsal üretiminde artışın sağlanmasının yanında; sulama, gübre ve pestisit gibi tarımsal girdi kullanımında azalmaya bağlı olarak çevre kalitesinin yükselmesine de yardımcı olmaktadır (Mohanty et al., 2007). Tarım arazilerinin sürdürülebilirliği toprağın fiziksel, kimyasal ve biyolojik özelliklerinin belirlenmesine, mevcut durumunun korunması için uygulanacak toprak-bitki yönetiminin seçimine bağlıdır. Toprakların verimliliğ̆i sonsuz olmadığı için toprağın mevcut durumu bilinmeli, belirlenen durumlara göre yöntemler seçilmelidir. Toprak özelliklerinin bozulması insanın doğrudan etkisi ile kontrol edilemez bir durum haline gelmektedir. Toprak özelliklerinin bozulması toprağın erozyona karşı direncinin azalmasına, canlı çeșitliğinin azalmasına sonuç olarak da toprağın sürdürülebilirliği olumsuz yönde etkilemektedir. Toprak kalitesi doğal veya yönetilen ekosistem içerisindeki bir toprağın bitkisel ve hayvansal üretimi sürdürebilme, su ve hava kalitesini artırabilme ve insan sağlı̆̆ için uygun yaşam ortamını oluşturma fonksiyonlarının tamamını sağlayabilme kapasitesi olarak tanımlanmaktadır (Karlen et.al., 1997; Doran, 2002). Toprak kalitesi değerlendirmelerinde doğal ve dinamik toprak özelliklerinin yanı sıra toprak oluşum süreçleri ve toprakların etkileşimleri bütünsel olarak değerlendirmeye katılmalıdır (Karlen et al., 2003). Toprak kalitesi parametreleri kolayca ölçülebilmeli, toprak fonksiyonlarındaki değişiklikleri yansıtabilmeli, toprak yönetimi değişikliklerine duyarlı olabilmeli ve birçok kullanıcının bilgilere kolayca ulaşabilmelidir (Shukla et. al., 2006). Toprak 
kalitesi ya da toprak kalitesinin fonksiyonu pek çok faktörün karşılıklı etkileşimini sağlar. Sürdürülebilirlik toprak kalitesine bağlıdır. Herhangi bir toprağın kapasitesi, doğal veya yönetilen sınırlar çerçevesinde toprağın üretkenliğini sağlamak ve sürdürmek ya da; topak ve su kalitesi ve insan sağlığı ve doğal çevreyi desteklemekle geliştirilir (Mohanty et al., 2007). Toprak kalitesi temel toprak fonksiyonlarını etkiler, bunlar suyun iletimi ve bitkilere çözünen madde hareketi ve bunların yeniden dağıtımı; besinlerin depolanması ve döngülenmesi; filtrelemek, tamponlamak, bloke etmek ve organik ve inorganik maddeleri toksinlerden ayrıştırmak; kök büyümesini sağlamak; erozyona dayanıklılığını sağlamaktır. Toprak kapasitesinin fonksiyonu ölçümlenmiş toprağın fiziksel, kimyasal ve biyolojik özellikleri tarafından yansıtılabilir bunlar ayrıca toprak kalite indeksi olarak bilinir (Shukla et al., 2006). Yaygın olarak kabul edilen toprak kalitesi tanımına göre toprak kalitesi, bitkiler ve hayvanlardaki ekosistemde işler ayrıca hava ve su kaynaklarının birleşimini oluşturur. Kompleks fonksiyonel durum olarak, toprak kalitesi direkt olarak ölçülemez, ama ölçülebilir toprak özellikleri tarafından toprak kalite indeksi özellikleri olarak adlandırılır. Bunun yanında, toprak kalitesi değerlendirmeleri toprağın kimyasal ve fiziksel özellikleri üzerinde yoğunlaşmıştır. Çünkü ölçümlerin basit metodları yeterlidir. Son zamanlarda toprağın biyolojik ve biyokimyasal özelliklerinin tarımsal ekosietem stresinin veya toprak verimliğindeki değişikliklerin erken ve hassas göstergeleri olarak kullanılabileceği iddia edilmiştir (Islam and Weil, 2000).

Bu çalışma Doğu Karadeniz Bölgesinde yaygın olarak bulunan podzolik toprakların farklı kullanım koşulları altındaki durumlarını toprak kalite parametrelerine göre değerlendirmek amaciyla yürütülmüştür.

\section{MATERYAL VE METOT}

Araştırma, Doğu Karadeniz Bölgesi’ nin karakteristik özelliklerini yansıtan Rize ilinde üç farklı şekilde kullanılan (orman, çayır, çay) alanlarda profil açılmış, ve toprak örneklemesi yapılmıştır (Şekil 1). Orman ve çayır arazileri Çamlıhemşin ilçesinde, çay tarımı yapılan arazi ise Ardeşen ilçesinde belirlenmiştir.

Rize'de yazları serin, kışları ılıman ve her mevsimi yağışlı bir iklim görülür. Yapılan rasat sonuçlarına göre Rize'nin yıllık sıcaklık ortalaması $14{ }^{\circ} \mathrm{C}$ civarındadır. Rize ili ülkemizin en çok yağış alan bölgesi olup uzun yıllar yağış ortalaması 2200 $\mathrm{kg} / \mathrm{m}^{2}$ 'nin üzerindedir. En çok yağış sonbahar döneminde düşmekte olup en düşük yağış ise ilkbahar döneminde düşmektedir.

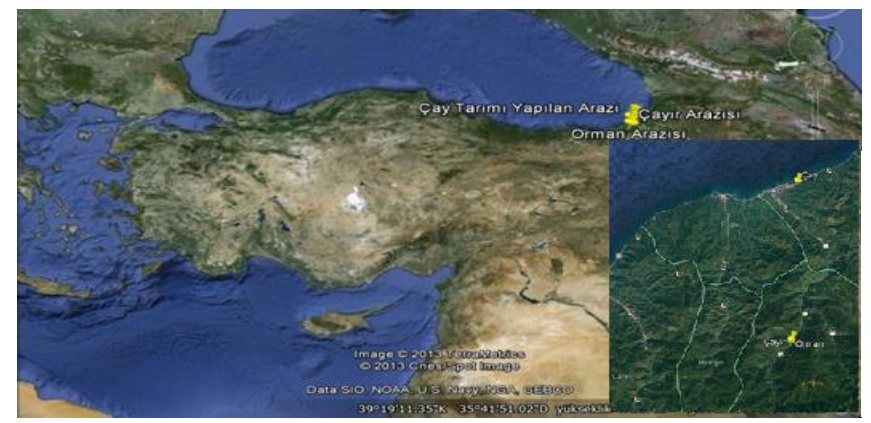

\begin{tabular}{|c|c|c|}
\hline Kullanim Sedki & Koordinat & Ralum (m) \\
\hline Oman & $41^{\circ} 00^{\prime} 23.75^{\prime \prime} \mathrm{K} ; 40^{\circ} 59^{\prime} 20.55^{\prime \prime} \mathrm{D}$ & 430 \\
\hline Cays & $41^{\circ} 00^{\prime} 31.99^{\prime \prime} \mathrm{K} ; 40^{\circ} 59^{\prime} 20.84^{\prime \prime} \mathrm{D}$ & 420 \\
\hline Cay & $41^{\circ} 11^{\prime} 34.60^{\circ} \mathrm{K} ; 40^{\circ} 59^{\prime} 52.20^{\prime \prime} \mathrm{D}$ & 5 \\
\hline
\end{tabular}

Şekil 1. Toprak örneklerinin alındığı yerler ve koordinatları

Çay, çayır, orman arazilerinde usulüne uygun olarak toprak örnekleri alınmıştır. Alınan örnekler laboratuvara getirilerek öncelikle hava da kurutulmuş dövülmüş sonra $2 \mathrm{~mm}$ ' lik elekten elenerek analiz edilmiştir. Toprak örneklerinde tekstür (Gee and Bauder, 1986), pH (McLean, 1982), kireç (Nelson, 1982), organik madde (Nelson and Sommers, 1982), katyon değişim kapasitesi (Rhoades, 1982), toplam azot (Kacar, 1966), fosfor (Aydın ve Sezen, 1995), agregat stabilitesi ve tane yoğunluğu (Demiralay, 1993), hidrolik iletkenlik (Klute and Dirksen, 1986), $\mathrm{Fe}, \mathrm{Mn}$ ve Al (Sağlam, 1994) analizleri yapılmıştır.

\section{Toprak kalite indeks çalışmaları}

$\mathrm{Bu}$ çalışmada toprak kalitesi değerlendirme yöntemlerinden "Parametrik Yöntemlerle Arazi Kalite İndeksi", "MEDALUS", "Kalite Skor Tablosu" ve "Orman toprak sağlığı değerlendirmeleri için Toprak Kalite İndeksi”, olarak dört farklı yöntem kullanılmıştır.

\section{Parametrik yöntemlerle arazi kalite indeksi}

Parametrik metodu ilk olarak Riquier et. al., 1972‘ de arazi değerlendirmesi için önermişlerdir. Parametrik yaklaşımda her bir arazi karakteristiğinin sınırlayıcı faktörlerine bağlı olarak değişen düzeylere göre arazi değerlendirmesi işlemidir. Arazi kalite indeks değerlerinin hesaplanmasında tekstür, eğim, 
toprak derinliği, taşlılık, çalıllılık ve kayalılık durumu, tuzluluk, alakalilik ve $\mathrm{pH}$ ile diğer faktörlerin (yağış oranı, kök gelişmesini engelleyen sert katman, erezyon derecesi, drenaj, kireç, KDK ve Verimlilik) oranlarının toplanmasıly hesaplanmaktadır.

$$
\begin{gathered}
A K \dot{\mathrm{I}}=R_{\max } x \sqrt{\frac{A}{100}} \times \frac{B}{100} x \ldots . \times \frac{F}{100} \\
A K \dot{\mathrm{I}}=\text { Arazi Kalite İndeksi } \\
R \max =\text { Ortalama maximum oran } \\
A, B, \ldots, F=\text { Her bir faktörün oransal değeri }
\end{gathered}
$$

\section{MEDALUS (Mediterranean Desertification} and Land Use)

$\mathrm{Bu}$ indeks; toprak kalitesi, iklim, bitki örtüsü ve arazi yönetimi gibi parametrelerden oluşmaktadır (Kosmas et al., 1999).

MEDALUS medotu ile Toprak Kalite İndeksi (TKİ) belirlenmesi, çeşitli toprak karakteristiklerine bağlı olarak;

$$
T K \dot{\mathrm{I}}_{\mathrm{i} J}=\left[\left(f a k t o ̈ r_{-} 1_{i j}\right)\left(\text { faktör }{ }_{-} 2_{i j}\right)\left(\text { faktör_ } 3_{i j}\right) \ldots\left(\text { faktör_ } n_{i j}\right)\right]^{1 / n}
$$

\section{Kalite skor tablosu}

Tarım topraklarının kalitesini belirlemede, Doran and Parkin (1994) tarafindan, gida ve tarımsal ürün verimi, yer altı suyu kalitesi, yüzey suyu kalitesi, toprak kayıp limitleri, hava ve ürün kalite değerleri olmak üzere toplam 6 kalite kriterinin ölçü alınabileceği önerilmiştir. Arazi kalitesi belirlenecek alanın çeşitli yerlerinden alınan toprak örneklerinin analizleri sonucunda veri seti hazırlanmışır.

\section{Orman toprak sağlığı değerlendirmeleri için toprak kalite indeksi}

Orman Toprak Sağlığı Değerlendirmeleri için ilgili özel sorunlar ele alınarak, toprakların kimyasal ve fiziksel birtakım özelliklerini ölçülmesine dayalı TKİ aşağıdaki formülle belirlenmiştir (Amacher et. al., 2007).

$$
T K \dot{\mathrm{I}}=\frac{\sum i}{\operatorname{Max} \cdot i} \times 100
$$

TKI $=$ Toprak Kalite İndeksi

$\sum \mathrm{i}=$ Ölçülen toprak paramatrelerinin İndeks değerleri toplamı

Max.i=Maksimum İndeks değerleri toplamı

\section{BULGULAR VE TARTIŞMA}

Örnekleme noktalarında açılan profillerin belirlenen horizonlarından alınan toprakların fiziksel ve kimyasal analiz bulguları Çizelge 1'de verilmiştir. Analizi yapılan toprak örneklerinin geneli kumlu tın ve killi tın sınıflarına ait olduğu belirlenmiştir. Çay tarımı yapılan arazide kil miktarının orman ve çayır arazisine göre yüksek olduğu görülmektedir. Her üç örnekleme noktasında da profil derinliğine bağlı olarak kil içeriğinin arttığı görülmektedir. Bu durum yağışın bol olduğu bölgelerde kilin yıkanarak alt horizonlarda birikebildiğini göstermektedir. Toprak örneklerinin $\mathrm{pH}$ değerleri tüm toprak örneklerinin asit karakterli olduğu belirlenmiştir. Çay tarımı yapılan alanda toprakların aşırı derecede asit sınıfında yer aldığı belirlenmiştir. Çay tarımı yapılan alanda $\mathrm{pH}$ değerlerinin horizonlar arasında ciddi bir değişme olmayıp, en yüksek pH değeri A horzionunda tespit edilmiştir. Çay tarımı yapılan alanda pH'nın diğer arazi kullanım şekillerine göre düşük olmasında gübrelemenin önemli ölçüde etkili olduğu düşünülmektedir (Barik vd., 2013). Çayır arazisinin toprak reaksiyonu verilerini incelediğimizde hafif asit karakterli olduğu görülmektedir (Özyazıcı vd., 2014). Çayır alanında da $\mathrm{pH}$ değerleri horizonlar arasında değişmekte olup, en düşük değer A1 horizonunda, en yüksek değer ise B1 horizonunda bulunmuştur. Orman arazisinden alınan toprak örneklerinin $\mathrm{pH}$ değerlerine bakıldığında orta derece asit olduğu belirlenmiştir. Orman arazisinde de horizonlar arasında $\mathrm{pH}$ değerleri değişmektedir. Organik horizon hariç alt horizonlara inildikçe $\mathrm{pH}$ değerleri artmakta olup, bu duruma bağlı olarak da asitleşme derecesi azalmaktadır. Toprak reaksiyonu, makro ve mikro besin elementlerinin yarayışlılığını etkilemektedir. Asit topraklarda değișebilir hidrojen, alüminyum ve mangan bitkilere zehir etkisi yapacak seviyeye kadar artabilir (Dalgliesh, 2006). Rize ilinin son 52 yıllık, aylık yağış ortalamasının $186 \mathrm{~kg} / \mathrm{m}^{2}$ olmasından dolayı bazik katyonların yıkanması soncunda bu bölgede bulunan topraklar asit karakterli yap1 göstermektedir. Doğu Karadeniz bölgesinde çay bahçelerinin tesis edildiği yıllarda topraklar $\mathrm{pH}$ yönünden en uygun koşulları sunarken, yıllar geçtikçe bu değerler değişmiştir. Bu hızlı değişmenin en önemli nedenlerinden biri, yörede tek taraflı ve yüksek dozda kullanılan amonyum sülfat gübresi oluşturmuştur (Kacar, 1984; Müftüoğlu ve Sarımehmet, 1993). Uzun zaman fosforik asit ve amonyum sülfat kullanımının toprak asitliğini artırdığı bilinmektedir. Sürekli kullanılan amonyum sülfat gübresinin $\mathrm{pH}$ değerlerinde düşmeye neden olduğu birçok araştırmacı tarafından belirtilmektedir (Sivasubramaniam and Talibudeen, 1972; Karim et al., 1981; Wickremasinghe et al., 1981). 


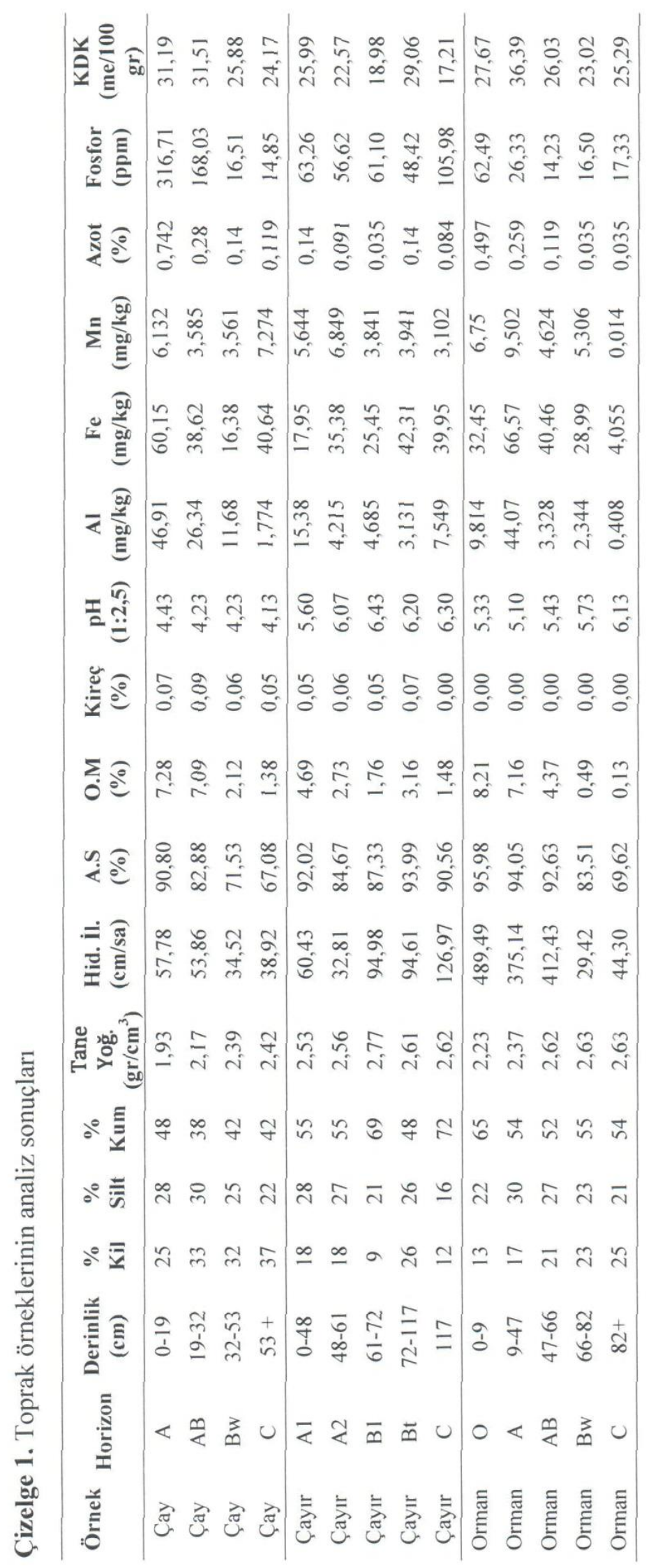


Örnekleme yapılan tüm alanlarda kireç içeriği çok düşük olarak belirlenmiştir. $\mathrm{Bu}$ da yıllık yağışın 2000 mm'nin üzerinde olması nedeni ile topraktaki kireci yıkayarak uzaklaştırdığını göstermektedir. Çay tarımı yapılan arazide kireç miktarlarının horizonlar arasında ciddi bir değişim olmadığ 1 görülmektedir. Çayır araziden alınan örneklerin kireç içerikleri çay tarımı yapılan araziden düşük, orman arazisinden yüksek bulunmuştur. Orman arazisinden alınan örneklerimizin sonuçlarında hiç kireç bulunmamıștır. Kirecin y1kanması bitki besin elementi noksanlığ yanısıra $\mathrm{pH}$ 'nın da düşmesine neden olması tarımsal üretimi olumsuz olarak etkileyecektir (Barik vd., 2013). Çay ve Çayır arazisine göre orman arazisi insan faaliyetinden çok uzak olmasından (kireçleme, gübreleme vb.) profillerde bulunan kirecin ylllarca yıkanması sonucunda horizonlarda kireç bulunamamamıștır. $\mathrm{Bu}$ durum yıkanmanın etkin olduğu podzolik toprakların tipik bir göstergesidir.

Toprak örneklerinin organik madde miktarları tüm örnekleme noktalarının solum tabakasında yüksek olduğu belirlenmiştir. Tüm toprak örneklerinde derinlikle birlikte OM seviyeside azalmaktadır. Bitkisel atıkların en fazla toprak yüzeyine düşmesiyle yă̆ı̧ıı bol, sıcaklığın serin olmas1 toprakta OM birikimine neden olmaktadır (Boyle et al., 1989; Arshad and Coen, 1992). Her türlü bitkisel ve hayvansal atık, toprağa ulaştığında biyolojik ve kimyasal tepkimelerle ayrışmaya, yeni ürünler oluşturmaya başlar. Organik madde mikroorganizmaların temel besini olmasının ve bitkilere besin kaynağı görevi yapmasının yanı sıra, toprakta fiziksel ve kimyasal olayların yürümesinde de etkilidir. İyi havalanma, bol su tutma, su ve hava iletkenliği, erozyona karşı direnç, toprak yapısının gelişmesi ve işlemenin kolaylaşması, besin maddelerinin bitkilere hazır durumda tutulması, zehirlere ve asitlik-alkaliliğe karşı tamponluk gibi görevlerde organik maddenin payı büyüktür (Chenu et al., 2000). Organik madde kapsamı yüksek olan toprakların kolay işlendiği, daha fazla su tutup daha uzun süre nemli kaldığı, verimli olduğu, erozyona karş1 direndiği gibi özellikler, çağlardan beri bilinmektedir (Ünver vd., 2013).

Toprak örneklerinin KDK miktarlarının tüm arazilerde yüksek olduğu belirlenmiştir. Çay ve çayır alanlarında KDK değerleri genellikle alt horizonlara inildikçe azalmatadır. $\mathrm{Bu}$ durum alt horizonlarda organik maddenin azalması ile açıklanabilir.

Toprak örneklerinin çay ve orman arazilerinde $\mathrm{N}$ miktarları alt katmanlara inildikçe azalmaktadır.
Çay arazisinin yüksek miktarda $\mathrm{N}$ barındırmasının nedeninin gübrelemeden kaynaklı olduğu düşünülmektedir.

Topraklarının Al durumları üç örnekleme noktasının A horizonunda en yüksek seviyede olduğu belirlenmiştir. Çay ve orman arazilerinde genellikle alt horizonlara inildikçe Al miktarları azalmaktadır. Yalnız orman arazisin yüzey horizonu(organik horizonu)' nun $\mathrm{Al}$ seviyesi A horizonuna göre düşük bulunmuştur. Çayır arazisinde $\mathrm{Al}$ seviyeleri horizonlar arasında değişmektedir. Yüzey toprakları asit reaksiyon göstermesinden dolayı $\mathrm{Al}$ seviyelerinin yüksek çıkması bu duruma bağlanabilir. Alüminyum üzerine yapılan bazı araştırmalar neticesinde genellikle 50 ppm üzeri değerlerde bitkiler üzerinde ciddi toksisite belirtileri ortaya çıkmaktadır (Alfredsson et al., 1998). pH'sının düşmesiyle toprakların Al içerikleri yükselmekte tarımsal ürünlere zehir etkisi yapacak boyutlara ulaşabilmektedir. $\mathrm{Bu}$ durum birçok araştırmacı tarafindan da ifade edilmiştir (Chen et al., 1973; Koffa and Mori, 1987; Alfredsson et al., 1998).

Tüm örneklem noktalarında hidrolik iletkelik değerleri yüksek çıkmış olup "çok hızlı" geçirgenlik sinıfında yer almaktadırlar. En yüksek hidrolik iletkenlik değeri Orman arazisin organik horizonunda görülmektedir. Çay tarımı yapılan alan ile orman örtüsü altındaki toprakların hidrolik iletkenlik değeri derinlikle birlikte azalırken çayır örtüsü altındaki toprakta derinlikle birlikte artış olduğu görülmüştür. Orman arazinde horizonlar arasında yüksek bir fark olmasının nedeni $\mathrm{B}$ ve $\mathrm{C}$ horizonlarındaki kil yüzdesinin fazla olması ve AS değerlerinin üst horizonlara göre düşük olmasından kaynaklanabilir. Çayır örtüsü altındaki topakta hidrolik iletkenliğin yüksek çıkması yüksek agregat stsabilitesi ile bağdaştırılabilir. Hidrolik iletkenlik toprağın geçirgenliğinin bir göstergesi olduğundan dolayı tekstür sınıfı ve AS ile doğru orantılı çıkması yapılan çalışmanın uygunluğunu göstermektedir. Toprakta kum miktarı ve AS oranı artıkça hidrolik iletkenlik artmakta ve buna bağlı toprağın geçirgenliği artmaktadır (Dumanski and Pieri, 2000).

\section{Parametrik yöntemlere göre arazilerin kalite durumları}

Parametrik yöntemle toprakların AKİ (Arazi Kalite İndeksi) değerleri hesaplanarak Çizelge 2'de belirtilmiştir.

Çizelge 2. Parametrik yönteme göre arazilerin kalite durumları

\begin{tabular}{|c|c|c|c|}
\hline Arazi & \% AKI & Uygunluk Sınıfi & Durumu \\
\hline Çay & 65,48 & S2 & İyi \\
\hline Çayır & 71,13 & S2 & Iyyi \\
\hline Orman & 64,13 & S2 & Iyi \\
\hline
\end{tabular}

$\mathrm{Bu}$ hesaplamada kullandı̆̆ımız prametreler toprağın tekstürü, eğim durumu, solum derinliği, taşlilık durumu, tuzluluk, alkalilik, toprağın reaksiyonu, yıllık yağış, sınırlayıcı katman, drenaj, 
kireç, KDK, verimlilik durumları kullanılmıştır. Parametrik yönteme göre toprakların S2 uygunluk sınıfinda olduğu ve kalite durumlarının ise iyi oldukları belirlenmiştir.

\section{MEDALUS'a göre arazilerin kalite} durumları

MEDALUS projesinde kullanilan hesaplama modeliyle araştırma alanında belirlenen sonuçlara göre toprakların Toprak Kalite İndeksi (TKİ) değerleri hesaplanarak Çizelge 3 'te belirtilmişstir.

Çizelge 3. MEDALUS yönteme göre arazilerin kalite durumları

\begin{tabular}{|c|c|c|}
\hline Arazi & TKं & Durumu \\
\hline Çay & 1,22 & Orta Kalite \\
\hline Çayır & 1,22 & Orta Kalite \\
\hline Orman & 1,26 & Orta Kalite \\
\hline
\end{tabular}

$\mathrm{Bu}$ hesaplamada; tekstür, taşlılık durumu, drenaj, eğim ve ana materyal parametreleri kullanılarak kalite durumları belirlenmiştir. $\mathrm{Bu}$ hesaplama metoduna göre her üç kullanım durumunda da toprakların Orta kalitede olduğu belirlenmiştir.

\section{Kalite skor tablosuna göre arazilerin kalite} durumları

KST'na göre toprakların Kalite Skor Değeri (KSD)'leri Çizelge 4'te belirlenmiştir.

Çizelge 4. Kalite Skor Tablosu yönteme göre arazilerin kalite durumları

\begin{tabular}{|c|c|c|}
\hline Arazi & KSD & Durumu \\
\hline Çay & 2,8 & Kaliteli \\
\hline Çayır & 3,4 & Kaliteli \\
\hline Orman & 3,4 & Kaliteli \\
\hline
\end{tabular}

KST'de kullanılan parametreler organik madde, $\mathrm{pH}$, renk, N, P, K durumu, Toprak verimliliği, taban suyu, infiltrasyon, drenaj, toprak derinliğidir. $\mathrm{Bu}$ hesaplama metoduna göre topraklarımız kaliteli oldukları belirlenmiştir.

\section{Orman toprak sağlığı değerlendirmelerine} göre arazilerin kalite durumları

Orman toprak sağlığı değerlendirmeleri için hazırlanan TKI' ye göre bulunan değerler Çizelge 5 'te belirtilmiştir.

Çizelge 5. Orman toprak sağlı̆̆ değerlendirmeleri yöntemine göre arazilerin kalite durumları

\begin{tabular}{|c|c|c|}
\hline Arazi & \% TKI & Durumu \\
\hline Çay & 72,2 & İyi \\
\hline Çayır & 77,7 & İyi \\
\hline Orman & 83,3 & Çok İyi \\
\hline
\end{tabular}

Orman toprak sağllğ değerlendirmeleri için kullanılan hesaplama modeliyle, araştırma alanımızda belirlenen sonuçlara göre toprakların Toprak Kalite İndeksi (TKİ) değerleri hesaplanmıştır. $\mathrm{Bu}$ hesaplamada kullanılan parametreler; taşlılık durumu, organik madde, $\mathrm{N}$, değişebilir $\mathrm{Na}, \mathrm{pH}$ ve mikroelement miktarlarıdır. Bu metoda göre Çay ve Çayır alanlarının toprak kalite durumları iyi, orman arazisin kalite durumu ise çok iyi olduğu belirlenmiştir.

\section{SONUC}

$\mathrm{Bu}$ çalışmada ülkemizin kuzeyinde yer alan Doğu Karadeniz bölgesinde yaygın olarak bulunan podzolik topraklarda farklı kullanım koşulları altında toprak kalite durumlarını belirlenmiştir.

Organik madde; toprağın birçok fiziksel, kimyasal ve biyolojik özelliklerini doğrudan veya dolaylı olarak olumlu etki etmektedir. $\mathrm{Bu}$ nedenle toprak örneklerinin O.M miktarı her üç örnekleme noktasında da toprak kalitesini olumlu yönde artırmıştır.

Örnekleme bölgesi çok yağış alan bir bölgedir. Yağışların etkisiyle birçok element topraktan yıkanarak uzaklaşmakta toprakta $\mathrm{Al}$ katyonlarının artmasına neden olduğundan topraklar asitleşmektedir. $\mathrm{Bu}$ nedenle bu yöre toprakları için $\mathrm{pH}$ önemli bir kalite parametrelerindendir. Aynı zamanda, Al miktarındaki artış bitkilere toksik etki yapabilmektedir. Bu nedenle toprakların Al miktarı toprak kalitesini olumsuz yönde etkilemiştir.

Bölge topraklarının aldığı yıllık yağıŞ miktarının yüksek olmasına rağmen, sahip oldukları KDK değerinin yüksek olması toprakta bulunan elementleri tutulabilme kapasitesini arttırmaktadır. KDK kapasitesinin yüksek olması toprak kalitesini de olumlu yönde etkilemiştir.

Hidrolik iletkenlik, toprağın suyu iletme yeteneğinin bir ölçüsü olduğundan ve toprakta strüktür gelişimini dolayısı ile stabiliteyi olumlu yönde etkileriğinden toprakların kalitesini geliştirmiştir.

Topraklardaki agregatlaşma, toprakların su tutma ve havalanma kapasitesi, suyun ve havanın toprak içersindeki hareketi, kök gelişimi ve dağılımı, mikrobiyal toplulukların aktivitesi gibi birçok toprak özelliğini etkilemektedir. Agregat stabilitesinin yüksek çıkması toprak kalitesini olumlu yönde etkilemiştir.

Yöre toprakları aşırı yağış aldığından toprakta bulunan kireç yıkanarak topraktan uzaklaşmaktadır. Toprakların kireç miktarı çay tarımı yapılan alanda ve çayır bitki örtüsü ile kaplı alanda çok düşük iken orman örtüsü ile kaplı alanda hiç kireç bulunamamıştır. Kireç azlığı toprak pH'sını düşürmüş toprakların kalitesini olumsuz yönde etkilemiştir. 
Topraklar kullanılan metoda göre toprak kalitesi bakımından farklılıklar göstermiştir. Bu durum her bir metodun kullanım amacının birbiri ile aynı olmadığını göstermektedir. Değerlendirmede amaca uygun metodun seçilip kullanılması toprak yönetim uygulamaları bakımından önem arz etmektedir.

Yapılan analizleri arazi kullanım durumuna göre birlikte ve kullanılan toprak kalitesi yöntemlerinden bağımsız olarak değerlendirdiğmizde ise doğal örtü olan orman arazileri için bir problemin bulunmadığı çayır olarak kullanılan arazilerde zaman zaman kireçlemenin yapılmasının toprağn verim ve üretkenliğini olumlu olarak etkileyeceğini, ifade edebiliriz. Fakat, çay tarımı yapılan alanda ise yapılan yanlış tarımsal uygulamaların toprağın verimini olumsuz yönde etkilediği söylenebilir. Bu durum toprakların önlem alınmadığı takdirde ilerleyen zaman içerisinde verim kabiliyetinin önemli ölçüde düşmesine neden olacağını göstermektedir.

\section{KAYNAKLAR}

Alfredsson, H., Condron, L.M., Clarholm, M. and Davis, M.R., 1998. Changes in soil acidity and organik matter following the establishment of conifers on former grassland in New Zealand. Forest Ecology and Management.

Amacher, M.C., O’Neill, K.P., Perry, C.H., 2007. Soil Vital Signs: A New Soil Quality Index (SQI) for Assessing Forest Soil Health,United States Department of Agriculture, USA

Arshad, M.A., Coen, G.M., 1992. Characterization of soil quality: Physical and chemical criteria. Am J Alternative Agric., 7: 25-31.

Aydın A., Sezen Y., 1995. Toprak Kimyası Laboratuvar Kitab1, Atatürk Ünversitesi Ziraat Fakültesi Ofset Tesisi, Yayın No: 174. Erzurum.

Barik K., Aydın A., Aydın C.K., 2013. Leaching of different liming materials from acid soil and determination of liming period. Journal of Food. Agriculture and Environment, 11 (3-4): 863866.

Boyle, M., Frankerberger, J., Stolzy, L.H., 1989. The Influence of Organic Matter on Soil Aggregation and Water Infiltration. J. Prod. Agric., 290-299.

Chen, Y.S.R., Butier, I.N., Stumn, W., 1973. Adsorbtion of Phosphate on Alumina and Kaolonite from Dilute Aqueous Solutions. J. Colloid lnterface Sci., 43: 421-436.

Chenu, C., Y.L Bissonnais, Arrouays, D., 2000. Organic Matter Influence on Clay Wettability and Soil Aggregate Stability. Soil Sci. Soc. Am. J., 64: 1479-1486.

Dalgliesh, N., 2006. Measure soil water for better farming decisions. Farming Ahead No:168
Demiralay, İ., 1993. Toprak Fiziksel Analizleri. Atatürk Üniversitesi. Yayınları No: 143. Erzurum, 90-95.

Dumanski, J., Pieri, C., 2000. Land quality indicators: resaarch plan. Agriculture, Ecosystems and Environment, 81: 93-102.

Doran, J.W., Parkin, T.B., 1994. Defining and assessing soil quality. In: Doran, J.W., Coleman, D.C., Bezdicek, D.F., Stewart, B.A. (Eds.), Defining Soil Quality for a Sustainable Environment. SSSA Special Publication No. 35, Madison, Wisconsin, USA.

Doran, J.W., 2002. Soil Health and Global Sustainability: Translating Science into Practice. Agriculture, Ecosystems and Environment, 88: 119-127.

Gee, G.W., Bauder J.W., 1986. Particle-Size Analysis. Methods of Soil Analysis. Part 1. Physical and Mineralogical Methods Second Edition. Agronomy, No: 9, 2. Edition, pp. 383441.

Islam, K.R., Weil R.R., 2000, Soil quality indicator properties-in mid-Atlantic soils as influenced by conservation management. Journal of Soil and Water Conservation, 55 (1): 69-78.

Karlen, D.L., Mausbach, M.J., Doran, J.W., Cline, R.G., Harris, R.F., Schuman, G.E., 1997. Soil quality: a concept, definition, and framework for evaluation. Soil Sci. Soc. Am. J., 61: 4-10.

Karlen, D.L., Ditzler, C.A., Andrews, S.S., 2003. Soil quality: why and how? Geoderma, 114: 145-156.

Kacar, B., 1966. Bitki ve Toprağın Kimyasal Analizleri. I. Genel Bilgiler. Ankara Üniversitesi. Ziraat Fakültesi Yayın No: 279, Ankara Üniversitesi Basımevi, Ankara.

Kacar, B., 1984. Çayın gübrelenmesi, Çay İşletmeleri Genel Müdürlüğü, Çay-Kur yayınları No: 4, Ankara.

Karim, Z., Rahman A., Rahman S., 1981. Mineralogy of acidic tea soils and sorption of phosphate. Tea Quartely, 50 (4).

Klute, A., Dirksen, C., 1986. Hydraulic Conductivity and Diffusivity: Laboratory Methods. Methods of Soil Analysis. Part 1. Physical and Mineralogical Methods. 2nd Edition. Agronomy No: 9. 687-734, 1188 p, Madison, Wisconsin USA.

Koffa, S.N., Mori, T., 1987. Effects of $\mathrm{pH}$ and aluminium toxicity on the grovvth of four strains of Leucaena leucocephala (Lam.) de Wit., Leucaena Research Reports, 8: 58-62.

Kosmas, C., Kurkby M., Geeson N. 1999. The Medalus Project Mediterranean Desertification And Land Use, European Communities.

Mc Lean, E.O., 1982. Soil pH and Lime Requirement. Methods of Soil Analysis Part2. 
Chemical and Microbiological Properties Second Edition. Agronomy. No: 9 Part 2. Edition p: 199-224.

Mohanty, M., Painuli, D.K., Misra, A.K., Ghosh, P.K., 2007. Soil quality effects of tillage and residue under rice-wheat cropping on a Vertisol in India. Soil \& Tillage Research, 92: 243-250.

Müftüoğlu, M., Sarımehmet, M., 1993. Doğu Karadeniz Bölgesi' nde Çay Tarımı Yapılan Toprakların Asitlik Durumu, Ege Üniversitesi, Ziraat Fakültesi, 30 (3), İzmir.

Nelson, D.W., Sommers, L.E. 1982. Organic Matter. Methods of Soil Analysis Part 2. Chemical and Microbiological Properties Second Edition. Agronomy. No: 9 Part 2. Edition pp. 574-579.

Nelson, R.E., 1982. Carbonate and Gypsum. Methods of Soil Analysis. Part 2. Chemical and Microbiological Properties. 2nd Edition. Agronomy No: 9. 181-197, 1159 p, Madison, Wisconsin USA.

Rhoades, J.D., 1982. Soluble Salts. Methods of Soil Analysis. Part 2. Chemical and Microbiological Properties. 2nd Edition. Agronomy No: 9, 167179, 1159 p, Madison, Wisconsin USA.

Riquier, J., 1972. A mathematical model for calculation of agricultural productivity in terms of parameters of soil anc climate. Paper AGL: 14.Sept. p: 9. FAO.
Özyazıcı, M.A., Sağlam, M., Dengiz, O., Erkoçak, A., 2014. Çay Tarımı Yapılan Topraklara Yönelik Faktör Analizi ve Jeoistatistik Uygulamaları: Rize İli Örneği. Toprak Su Dergisi, 3 (1): 12-23.

Sağlam, T., 1994. Toprak Kimyası. Trakya Üniv. Tekirdağ Ziraat Fakültesi Yayın No:190, Ders Kitabı No:21, Tekirdağ.

Shukla, M.K., Lal, R., Ebinger M., 2006. Determining soil quality indicators by factor analysis. Soil \& Tillage Research 87: 194-204.

Sivasubramaniam, S., Talibudeen, O., 1972. Effect of aluminium on growth of tea and uptake of potassium and phosphrus. The Tea Quarterly, 43: 4-13.

Ülgen, N., Yurtsever, N., 1984. Türkiye Gübre ve Gübreleme Rehberi. Tarım ve Orman Köyişleri Bakanlığı, Toprak Su Genel Müdürlüğü Araştırma Dairesi Başkanlığı, 47-48, Ankara.

Ünver İ., Çokuysal, B., Anaç, D., Kılıç, C., Eryüce, N., Kılıç, Ö., Esetlili, B., 2013. Toprak Bilimi ve Bitki Besleme. Anadolu Üniversitesi, Açıköğretim Fakültesi, 231, Eskişehir.

Wickremasinghe, K.N., Sivasubramaniam, S., Nalliah, P., 1981. Urea Hiydrolysis in Some Tea Soils. Plant and Soil, 62 (3): 473-477. 